\title{
TECNICA
}

\section{VARIANTES DE PROCESSOS DE COLORAÇÃO PARA ESTUDO DO SISTEMA NERVOSO}

\author{
NYLCEO MARQUES DE CASTRO *
}

\section{I - Coloração para o estudo microscópico topográfico do sistema nervoso central.}

Em tôdas as numerosas técnicas para coloração das bainhas de mielina, esbarramos sempre com dificuldades relacionadas com o material usado ou com o tempo empregado em prepará-las. No processo agora proposto, contornamos o fator tempo, de muita importância, mòrmente quando desejamos coloração em grande número e para cursos de demonstrações. Adotamos a seguinte técnica:

1 - Em peças fixadas em formol a $20 \%$ e incluídas em parafina, são feitos cortes de 10 a 20 micra, que serão colados em lâminas pelo método de Zombathy;

2 - desparafinização, hidratação e mordançagem dos cortes pela solução de alúmen de ferro a $4 \%$, durante 15 minutos;

3 - lavagem rápida em água destilada;

4 - coloração durante 30 minutos em solução de $10 \mathrm{cc}$. de soluto saturado de carbonato de lítio em $90 \mathrm{cc}$. de água destilada. Desta nova solução, retiram-se $10 \mathrm{cc}$., que serão substituídos por $10 \mathrm{cc}$. de solução alcoólica de hematoxilina a 10\%;

5 - diferenciação no líqüido de Weigert (ferricianeto de potássio $2,5 \mathrm{gr}$., biborato de sódio $2,0 \mathrm{gr}$., água destilada q. s. p. $100 \mathrm{cc}$.) durante 2 a 10 minutos, após lavagem prolongada dos cortes em água corrente:

6 - lavagem demorada em água corrente e coloração de fundo (orange G 2 gr., eosina $1 \mathrm{gr}$., ácido fosfomolíbdico $0,5 \mathrm{gr}$., água destilada q. s. p. $100 \mathrm{cc}$.) durante 10 a 30 minutos;

7 - lavagem, desidratação e montagem em bálsamo do Canadá.

Em nosso laboratório temos obtido ótimas preparações, apresentando-se as fibras mielínicas em azul carregado e a substância cinzenta em alaranjado, sobres. saindo-se nela as células coradas em vermelho. O processo fơ empregado no ho. mem e em várias espécies de mamíferos, tais como cão, coelho, cobaia, gato e cavalo, comportando-se sempre de maneira satisfatória. Nos encéfalos de recémnascidos, torna-se necessária maior permanência dos cortes na solução de alúmen - 30 minutos - e menor diferenciação - 1 a 2 minutos.

\section{II - Método de impregnąãa das neurofibrilas.}

São do conhecimento de todos que trabalham em técnica histológica, as dificuldades para a obtenção de impregnações metálicas. $\mathrm{Na}$ variante que descrevemos, de um dos métodos de impregnação metálica das neurofibrilas de Ramón y Cajal (nitrato de prata-piridina), temos obtido resultados quase que constantes, $O$ processo foi empregacio pela primeira vez num bulbo de cação e posto em julgamento no Canadá, pelo Prof. Masson, o qual nos respondeu que achava a lâmina ótima, ressalvando, no entanto, que o processo poderia não dar os mesmos resultados em animais de sangue quente. Fizemos

* Assistente de Anatomia Descritiva e Tcpográfica da Escola Paulista de Medicina (Prot. João Moreira da Rocha). 


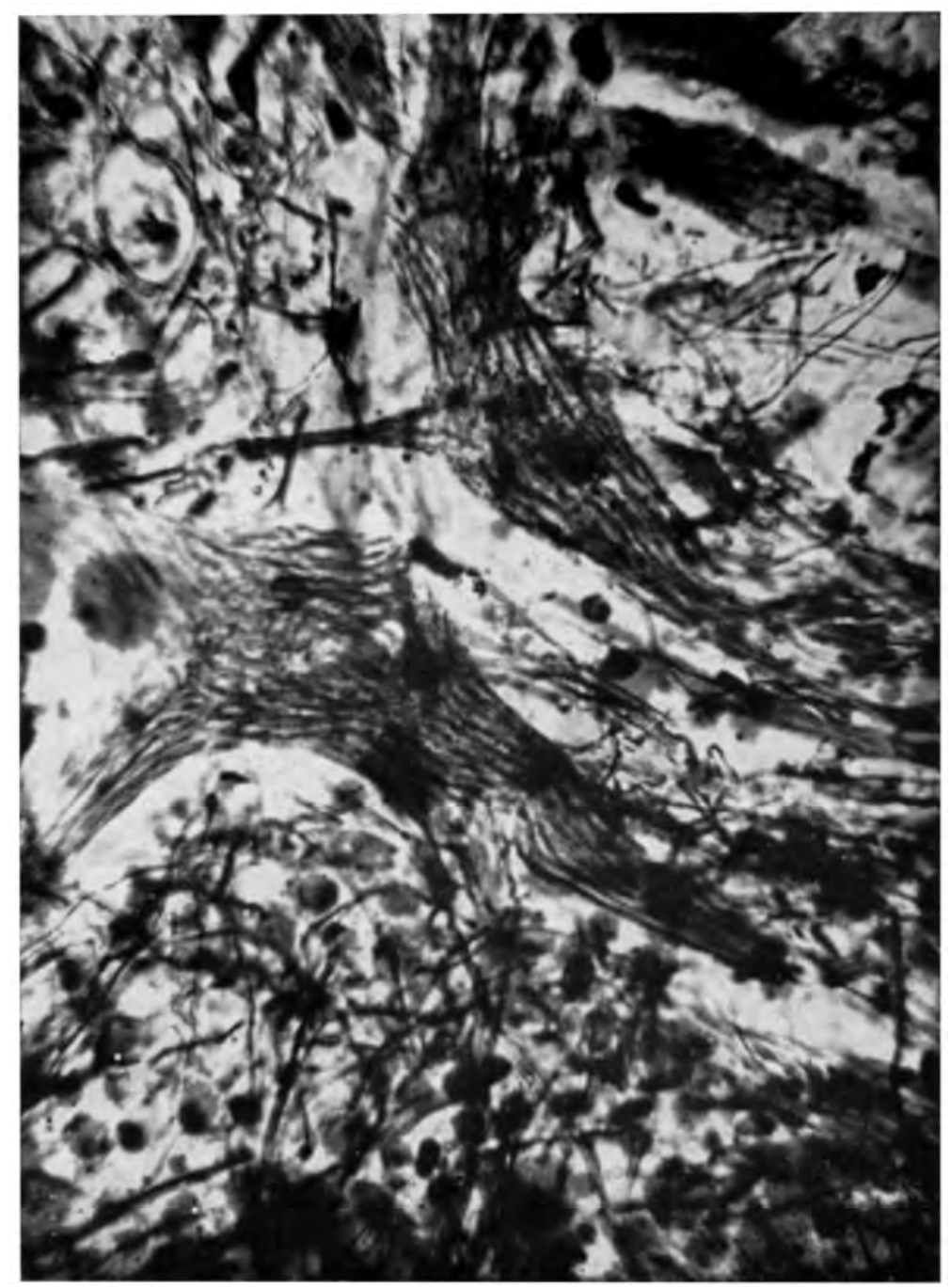

Fig. 1 - Microfotografia de bulbo raquidiano de cação com impregnação das neurofibrilas pelo método do autor. Notan-se duas células motoras. As manchas escuras na área ocupada pelos neurônios representam células satélites. $\mathrm{Na}$ célula maior, nota-se, com nitidez, a imagem negativa do núcleo. 


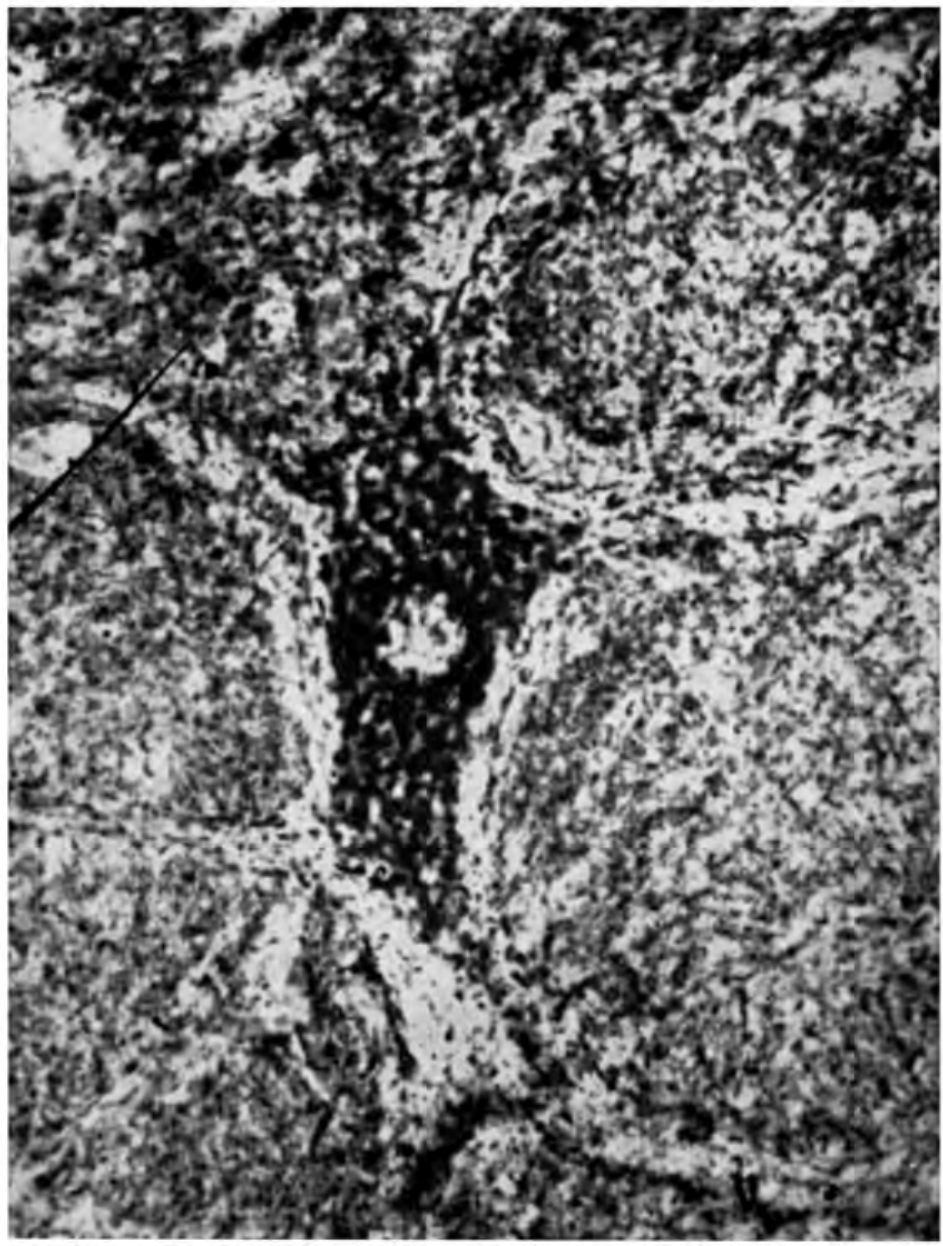

Fig. 2 - Microfotografia de célula motora do núcleo do hipoglosso do cão, com a substância tigróide impregnada pelo processo do autor $\mathrm{Na}$ parte central nota-se a imagem do núcleo. 
o que o Prof. Masson nos aconselhava e conseguimos obter aproximadamente as mesmas preparações; entretanto, as mais belas preparações sempre foram conseguidas em animais de sangue frio, principalmente naquele que nos tem servido de experiência. Usamos a técnica seguinte:

1 - Peças fixadas em formol a 20\%. Nos animais de sangue quente temos conseguido impregnações em peças fixadas durante dois meses, alargando-se êste tempo até seis meses, ou mais, nas peças de cação. O tempo nuínimo de fixação é de dois dias;

2 - cortes em congelação de 20 micra recolhidos em água amoniacal (uma gôta de amoníaco em 50 cc. de água destilada);

3 - os cortes são depois mantidos durante 12-24 horas na seguinte solução: juntam-se ràpidamente 30 gôtas de piridina a $10 \mathrm{cc}$. de nitrato de prata a $10 \%$, agitando-se rápida e fortemente até obter cristalização completa da solução Às vezes, depo:s das primeiras agitações, nada se obtem; deixise então o líqüido em repouso durante 30 segundos, para voltar de novo a agitá-lo até conseguir o desejado. Dissolve-se o cristalizado, ràpidamente, en 30 cc. de água destilada;

4 - lavagem rápida em álcool a 95.

5 - redução dos cortes na seguinte solução: água destilada 70 cc., hidroquinona $0,5 \mathrm{gr}$., formol neutro $20 \mathrm{cc}$., acetona $10 \mathrm{cc}$;

6 - lavagem em água destilada e viragem numa solução de cloreto de wuro a $0,2 \%$;

7 - fixação no hipossulfito de sódio durante 30 segundos;

8 - desidratação, diafanização e montagem em bálsamo do Canadá.

III - Método de impregnação metálica da substância tigróide.

Nos ensaios efetuados com o método do nitrato de prata-piridina de Ramón y Cajal, conseguimos, de modo imprevisto, impregnar a substância tigróide. Desejando preparar lâminas de demonstração, um de meus auxiliares aumentou de algumas vezes as quantidades indicadas pelo processo original e, ao mesmo tempo, por inadvertência, transportou-os diretamente do micrótomo à solução de nitrato de prata-piridina. Após hora e meia de permanência dos cortes nessa solução, fizemos uma lâmina seguindo as indicações de Ramón y Cajal e, com surprêsa, verificamos a substância tigróide impregnada, apresentando o mesmo aspecto daquele obtido pelas colorações com azul de toluidina de Nissl.

Pelas indicações de Ramón y Cajal (citado por Romeis), sua fórmula cora fibras musgosas, cálices de Held, terminações nervosas, placas motoras e "diversas particularidades do tec do nervoso, muscular e epitelial". Não conseguindo o trabalho original do autor, ficamos sem saber se, nas "diversas particularidades do tecido nervoso", o aútor incluia também a substância tigróide. Ao mesmo tempo, é de conhecimento daqueles que trabalham em técnica histológica do sistema nervoso, a pouca duração que apresentam as láminas de substância tigróide, fator êsse desagradável, mòrmente para quem cleve fazer coleções de lâminas para curso prático escolar. Sabemos aue, no processo do formol bromurado de Ramón y Cajal para glia, obtemos, mas não constantemente, a imprengnação da substância tigróide, que, entretanto, aparere alterada, em grumos arredondados e com o inconveniente das dificuldades do processo. Nossa variante técnica cons'ste no seguinte:

1 - Fixação das peças em formol neutro a $20 \%$ durante 3 dias;

2 - cortes em congelação de 25 a 30 micra, recolhidos em formol a $10 \%$;

3 - sem lavar, transporte direto e permanência de 1 a 2 horas na seguinte solução: nitrato de prata a $2 \% 50 \mathrm{cc}$, piridina 40 gôtas, álcool absoluto 25 cc.; 
4 - lavagem em álcool absoluto (8 a 10 segundos);

5 - redução até deixar de desprender nuvens esbranquiçadas, na seguinte solução: água destilada $70 \mathrm{cc}$, hidroquinona $0,3 \mathrm{gr}$.; acetona $15 \mathrm{cc}$;

6 - lavagem em água destilada;

7 - viragem no cloreto de ouro a $0,05 \%$ até ficarem purpuráceos;

8 - fixação no hipossulfito de sódio durante meio minuto;

9 - lavagem abundante em água destilada, desidratação e montagem em bálsamo do Canadá. Após desidratação, os cortes podem ser clarificados pelo líqüido de Hortega (xilol-ácido fênico-creosoto).

\section{RESUMO}

$O$ autor introduziu algumas modificações em processos de coloração para o estudo histológico do sistema nervoso central: 1 - No processo de coloração para a bainha de mielina, no estudo anatômico topográfico do sistema nervoso central, emprega a mordançagem e coloração pela hematoxilina e a rápida coloração celular pela mistura eosina-orange G-ácido fosfomolíbdico. 2 - No método das neurofibrilas tem observado melhores impregnações, cristalizando o nitrato de prata pela piridina e dissolvendo o cristalizado em água destilada. 3 - Para a impregnação metálica da substância tigróide, além de modificar as proporções usadas na confecção da prata-piridina e o tempo de ação da mistura, passa os cortes diretamente para a solução redutora.

\section{SUMMARY}

The author introduced some modifications in the staining techniques for the histological study of the central nervous system: 1 - To stain the myelin sheath in the anatomo-topographic study of the central nervous system, the author uses a mordant and staining by hematoxylin and a rapid cellular staining by the mixture eosin-orange G-phosphomolybdic acid. 2 To stain the neurofibrils better impregnation is obtained by crystalising the silver nitrate by pyridin and redissolving it in distilled water. 3 - For the metallic impregnation of the tigroid substance the author modified the proportions in the making of silver-pyridin and the time of its action. The sections are put directly in the reducing solution.

\section{RESUME}

L'auteur introduit quelques modifications dans les procedés de coloration pour les études histologiques du système nerveux central: 1 - Dans le procedé de coloration pour la gaine de myéline pour l'étude anatom:que topographique du système nerveux central, il emploit la mordançage et coloration par l'hématoxyline et la rapide coloration cellulaire par le mélange éosineorange G-acide phosphomolybdique. 2 - Pour la coloration de neurofibrilles, l'auteur a obtenu meilleures impregnations, en crystallisant le nitrate d'argent par la jyridine et, en suite, en employant la dissolution du crystallisé en eau distilleé. 3 - Pour l'impregnation métalique de la substance tigroïde, en plus de modifier les proportions employées à la confection de l'argent-pyridine et le temps d'action du mélange, il passe les coupures directemente dans la solution rédutrice.

$$
\text { Rua Pedro de Toledo, } 573 \text { - S. Paulo }
$$

